\title{
Die funksies van die raad van beheer: Teorie en praktyk
}

\author{
Chris F. van Veijeren \\ Skool vir Bedryfsleiding, Universiteit van Suid-Afrika, Pretoria
}

The functions of the board of directors: Theory and practice. A major difference seems to occur in practice between what the normally accepted functions of the board of directors are and what they actually do. As the ultimate body responsible for managing an organization, one would normatively expect them to set amongst other functions the strategy of the organization. Lack of detailed involvement, time and sometimes knowledge prevent them from actually doing so and it is argued that as far as strategy formulation is concerned, the board should perform an audit function to ensure that strategies are rationally set.

S. Afr. J. Bus. Mgmt. 1983, 14: $1-5$

Dit kom voor asof daar 'n groot verskil in die praktyk bestaan tussen wat as normaalweg die verwagte funksies van die raad van direkteure van 'n organisasie beskou word en wat hulle in werklikheid doen. As die uiteindelike liggaam wat vir die bestuur van 'n organisasie verantwoordelik is, sou dit verwag word dat hulle onder andere die strategie van die organisasie daarstel. 'n Gebrek aan gedetailleerde betrokkenheid, tyd en soms kennis verhoed hulle om dit werklik in die praktyk te doen. Daar word geargumenteer dat so ver as wat strategieformulering betref, behoort die raad 'n ouditfunksie te vervul om só te verseker dat strategieformulering rasioneel sal geskied.

S.Afr. Tydskr. Bedryfs/. 1983, 14:1-5

\section{Inleiding}

Die liggaam wat die uiteindelike verantwoordelikheid vir die rigtinggewing, die bestuur en die beheer van 'n organisasie dra, staan gewoonlik as die raad van beheer bekend. In SuidAfrika bestaan daar byvoorbeeld ten opsigte van landboubemarking sowat 22 verskillende beheerrade. Op 'n soortgelyke wyse word 'n organisasie soos 'n hospitaal deur 'n hospitaalraad, 'n skool deur 'n skoolraad en 'n universiteit deur 'n universiteitsraad beheer. In die geval van bedryfsorganisasies word hierdie raad normaalweg die raad, die direksie of die raad van direkteure en die persone wat daarop dien, die direkteure (en ook soms die direksie) genoem. Aan hierdie liggaam word die finale verant woordelikheid vir die doen en late van 'n organisasie opgedra en daarom is dit juis te meer opvallend hoe beperk die literatuur oor hierdie onderwerp veral ten opsigte van bedryfsorganisasies is. Hier te land is daar nog feitlik geen studies oor hierdie onderwerp uitgevoer nie en moet die Suid-Afrikaanse bedryfsleier hom tans nog in 'n groot mate op ontwikkelinge in die buiteland verlaat.

Daar heers vandag al hoe meer belangstelling in die aktiwiteite en die samestelling van die raad van direkteure, en hiervoor kan daar 'n hele aantal redes aangevoer word. Die eerste rede waarom hierdie onderwerp deesdae al hoe meer aandag van die topbedryfsleier ontvang, is die toenemende druk wat daar van owerheidsweë sowel as ander belanghebbendes (soos aandeelhouers) op die raad uitgeoefen word. Van die belangrikste aanleidende oorsake hiervoor was 'n aantal dramatiese ineenstortings van 'n aantal prominente maatskappye in Suid-Afrika sowel as in die buiteland. In Brittanje kan die naam van Rolls-Royce, in die Verenigde State van Amerika die Penn Central spoorwegmaatskappy, en in Suid-Afrika die ineenstorting van bekende eiendoms-en groeifondsmaatskappye as voorbeelde genoem word. 'n Aantal groot omkoopskandale het ook voorgekom. Een gemeenskaplike en ontstellende kenmerk in talle van hierdie maatskappye was die feit dat die direksies erg in die verleentheid was en moes erken dat hulle ò beheer oor die maatskappy verloor het en/òf nie oor die nodige inligting vir tydige optrede beskik het nie.

' $n$ Tweede rede vir die toenemende belangstelling in die werking van die raad van direkteure is dat die moderne bedryfsleier vandag besef dat 'n effektiewe en aktiewe raad 'n belangrike bydrae tot 'n effektiewe organisasie kan maak
Curis F. van Vedjeren

Professor, Skool vir Bedryfsleiding, Universiteit van Suid-Afrika,

Posbus 392, Pretoria 0001, Republiek van Suid-Afrika 
en hom gevolglik daarom daadwerklik in sy taak kan bystaan. Een van die beskuldigings wat dan ook dikwels tereg teen tradisionele rade geopper word, is dat sommige rade passiewe liggame is wat deur hulle besture gedomineer word en gevolglik slegs as die spreekwoordelike rubberstempel optree. Sulke rade kom in die praktyk ook slegs die minimum wetlike vereistes na. Verder kan daar op gewys word dat daar direkteure van Suid-Afrikaanse maatskappye is wat op 20 of 30 , soms tot soveel as 70 en in ten minste een geval op sowat 150 direksies dien. Die vraag wat dan onvermydelik in sulke gevalle ontstaan is of sodanige direkteure dan werklik in staat is om behoorlik tyd en aandag aan die aktiwiteite van elke maatskappy te gee. Hierdie vraagstukke het dan ook daartoe gelei dat die Suid-Afrikaanse wetgewing al hieroor hersien is in 'n poging om meer verantwoordelikheid van Suid-Afrikaanse direkteure te vereis.

Daar sal in hierdie artikel betoog word dat 'n effektiewe en aktiewe raad inderdaad ' $n$ belangrike en kritiese rol ten opsigte van die effektiwiteit van die organisasie as geheel te speel het. Die invloed wat deur die hoogste liggaam en die topbestuurder uitgeoefen word, kan deurslaggewend wees vir die daarstelling van 'n kultuur van prestasiebewustheid dwarsdeur die hele organisasie. Gevolglik sal daar verder in hierdie artikel gekyk word na wat die funksies van 'n effektiewe raad van direkteure behoort te wees. Die SuidAfrikaanse wetgewing ten opsigte van die rol van direkteure sal vervolgens ter sprake kom.

\section{Regsaspekte en die raad van direkteure}

In Suid-Afrika word die regsaspekte met betrekking tot direkteure van maatskappye deur die gemene reg en deur die maatskappywet (Wet 61 van 1973) en soos gewysig, gereël. Vir die nie-regsgeleerde is die kommentaar van onder andere Cilliers, Benade en De Villiers' ${ }^{1}$ besonder waardevol. Hulle wys daarop dat die benaming 'trustees' wat dikwels in regsbronne vir die direkteure as individue en as direksie gebruik word, onvanpas in die Suid-Afrikaanse reg is aangesien die benaming 'trustee' eienaarskap van trusteegoed in die Suid-Afrikaanse reg aandui, en 'die direkteur en direksie geensins eienaar van die maatskappybate is nie ....' (p.225).

'n Groot aantal sake ten opsigte van die administratiewe aangeleenthede in verband met die aanstelling, kwalifikasies, ontslag, register en so meer, word deur die Maatskappywet gereël. Van die algemene beginsels wat vir 'n direkteur onder andere van belang is, is die onregmatige behaling van voordele wat verkry word as gevolg van die vertrouensposisie waarin hy verkeer. So is dit byvoorbeeld ' $n$ misdryf om met binnekennis met aandele sake te doen ('insider trading') voor die openbare aankondiging van sake wat die prys van aandele of skuldbriewe van die maatskappy wesenlik kan beinvloed. Verder moet direkteure ook belange wat hulle regstreeks of onregstreeks mag hê by 'n kontrak of 'n voorgenome kontrak tussen die maatskappy waarvan hy 'n direkteur is en ander instansies, verklaar op 'n wyse soos deur die Wet voor geskryf word. Daar word ook 'n verbod op lenings aan direkteure en beamptes geplaas, behalwe in sekere gevalle soos behuisingslenings wat deur die Wet ingesluit word.

Die houding dat persone dikwels as direkteure gedien het ter wille van die vertroulike inligting wat op dié wyse verkry is en wat dan vir eie gewin aangewend is, het vir baie jare in talle lande bestaan. Een van die doelwitte met die verandering van die Maatskappywet was dan ook om die onregmatige bevoordeling van persone in vertrouensposisies te bekamp. Die persoon wat reeds dien of beoog om as direkteur te dien kan met vrug die Maatskappywet self en kommentare en publikasies daaroor lees. ${ }^{1,2}$ Uiteraard is die regsaspekte gespesialiseerd en waar 'n persoon nie self oor die nodige kennis beskik nie, is dit normaalweg raadsaam om ' $n$ regsgeleerde te raadpleeg indien daar enige onduidelikhede oor die korrekte wetlike optrede bestaan.

In die Amerikaanse wetgewing veral, word dit gewoonlik gespesifiseer dat die sake van 'n maatskappy 'shall be managed by a board of at least three directors'. Wat presies hiermee bedoel word, word egter nie in besonderhede deur die wetgewer omskryf nie. 'n Mens vind ook min leiding in die Suid-Afrikaanse Maatskappywet, 1973, oor wat die funksies van direkteure in Suid-Afrikaanse maatskappye moet wees. Die minimum benodigde aantal direkteure word wel gespesifiseer, maar andersins rig dié Wet hom basies tot beperkende regsaspekte soos die feit dat die direkteur skriftelik moet inwillig oor die voorgeskrewe vorm voordat hy as bevoeg geag word om as direkteur op te tree. Vanuit die bedryfsleidingoogpunt kan daar dus opgemerk word dat die regsliteratuur slegs die breë formele vereistes stel en min leiding aan die direkteur oor veral die positiewe strategieformuleringsaspekte gee.

\section{Funksies van direkteure}

Die bedryfsleier wat meer te wete wil kom oor wat die funksies van direkteure behoort te wees, vind dus betreklik min hulp by ' $n$ studie van die betrokke wetgewing en moet hom gevolglik tot die bedryfsleidingliteratuur wend. 'n Bekende klassieke studie oor hierdie onderwerp is dié een van Copeland en Towl $^{3}$ wat die volgende raadsfunksies onderskei het:

- Die verkryging van stabiliteit in 'n veranderende wêreld.

- Die seleksie van uitvoerende beamptes.

- Beleidsformulering.

- Die beheer van resultate.

- Die vra van skerpsinnige ('discerning') vrae.

'n Latere studie van die National Industrial Conference Board (NICB) noem sewe funksies waaroor daar 'n taamlike mate van eenstemmigheid bestaan: ${ }^{4}$

- Die vasstelling van die basiese doelstellings en breë beleidsaspekte van die onderneming.

- Die keuse van senior beamptes, die gee van advies aan hulle, die goedkeuring van hulle optrede en die ouditering van hulle prestasie.

- Die beskerming van, en die goedkeuring van verandering in, die bates van die onderneming. (Uitgifte van effekte, verpand van bates vir lenings, verklaring van dividende en die oordrag van eiendom.)

- Die goedkeuring van belangrike finansiële besluite en optrede (soos begrotings, die toedeling van kapitaal, die vergoeding van beamptes en finansiële oudits), en om toe te sien dat daar behoorlike jaarlikse en tussentydse verslae aan die aandeelhouers voorsien word.

- Die delegering van spesiale magte aan andere om kontrakte te teken, bankrekeninge te open, effekte uit te 
reik, lenings aan te gaan en enige ander aktiwiteite uit te voer waarvoor raadsgoedkeuring verleen moet word.

- Die instandhouding, hersiening en toepassing van die oprigtingsakte en die statute ('by-laws').

- Om toe te sien dat 'n effektiewe raad deur gereelde verkiesings en die vulling van tussentydse vakatures voortgesit word.

\section{Die werklike aktiwlteite van direkteure}

Mace het 'n breedvoerige studie oor die rol van direkteure in medium en groot Amerikaanse vervaardigings-, kleinhandel- en mynbouondernemings gedoen. Die belangrikste algemene strekking van sy bevindinge was dat daar aansienlike verskille is tussen die tradisionele funksies wat in die literatuur voorgehou word en die werklike funksies wat deur direkteure uitgevoer word.

Mace $^{5}$ het bevind dat die volgende drie funksies wel deur die raad van direkteure uitgevoer word:

(i) Die raad verleen advies en die geleentheid vir beraadslaging.

(ii) Die raad dien as 'n vorm van dissipline.

(iii) Die raad tree in krisissituasies op.

\section{Adviesverlening en beraadslaging}

Die raad se rol van adviesverlening en beraadslaging word dikwels in die praktyk met dié van 'n klankbord vergelyk. Die topleier kan in effek sy idees teen die raad toets. Die raad word dan ook dikwels met 'n kabinet vergelyk - dit is ' $n$ versameling van generaliste wat goeie advies van ' $n$ algemene aard kan lewer en nie noodwendig altyd met al die tegniese besonderhede vertroud is nie. Die raad word dan ook dikwels nie as 'n besluitnemingsliggaam beskou nie, maar as een waar daar tot 'n konsensus gekom word. Sake word bespreek en die gedagte is om tot 'n proses van ineenstemming te kom, selfs buite raadsvergaderinge, liewers as om sake tot 'n stemming te bring.

Tipiese areas waaroor advies gegee kan word, is op die tegnologiese gebied en die gebied van navorsing; finansiële aangeleenthede soos rentekoerse en finansieringsvoorwaardes; verhoudings met die staat; en selfs gebiede soos die eiendomswese en die landbou. Sommige lede mag ervaring van die buitelandse mark hê en reeds byvoorbeeld tot die uitvoermark toegetree het. Dit is dus duidelik dat indien 'n raad met sorg saamgestel is, daar 'n verskeidenheid van talente versamel behoort te wees wat ongetwyfeld as 'n waardevolle bron van kennis en oordeel beskou kan word.

\section{Die dissiplinêre waarde van die raad}

Die feit dat besluite ten minste vir formele goedkeuring aan die raad voorgelê moet word, impliseer dat daar waarskynlik heelwat meer aandag daaraan gegee sal word en gevolglik behoort die kwaliteit van die besluitneming te verhoog. In hierdie opsig dien die teenwoordigheid van die raad dus as 'n vorm van formele dissipline waaraan voldoen moet word. Sommige bedryfsleiers verwys na die raad as 'n ondernemingsgewete ('corporate conscience'). Hierdie teenwoordigheid van die raad help byvoorbeeld by die bepaling van realistiese vergoeding dat die voorstelle waarskynlik meer realisties en met meer verantwoordelikheid voorgelê sal word.

\section{Optrede in krisissituasies}

Die raad tree op wanneer veral twee krisissituasies in die praktyk voorkom. Hierdie is eerstens in die geval waar die topleier onverwags sou sterf en 'n plaasvervanger aangewys moet word. Indien die raad wel 'n sistematiese opvolgingsbeleid daargestel het, behoort die meriete van die moontlike opvolgers reeds met die topleier bespreek te gewees het en behoort die raad waarskynlik 'n geskikte persoon of persone in gedagte te hê. Sodanige optrede behoort die krisisafmetings van 'n onverwagte aftrede of afsterwe aansienlik te verminder.

'n Tweede krisissituasie wat kan voorkom, is dat die prestasie van die topleier so onbevredigend word dat die raad verplig is om 'n verandering te maak. Behalwe die onaangename emosionele aspekte wat gewoonlik aan so 'n besluit verbonde is, bestaan daar die probleem om die prestasie van die topleier op 'n objektiewe basis te meet. Daar is talle eksterne omgewingsfaktore wat so 'n meting bemoeilik. Daarby kom ook nog die menslik verstaanbare oorweging dat die topleier moontlik aan die raad inligting op so 'n wyse sal verskaf wat hom in so 'n gunstige lig as moontlik sal plaas.

Mace het bevind dat wanneer die vertoning van die topleier verswak, daar drie wyses is waarop die probleem benader kan word:

- Maak gebruik van 'n eksterne konsultant. Die gebruike van eksterne konsultante is een wyse van optrede wat in die praktyk gebruik word om aan 'n topleier dit tuis te bring dat sy prestasie kan verbeter. Die gebruik van konsultante om periodiek bestuursouditte waar te neem word in elk geval as deel van gesonde bestuurspraktyk beskou en behoort om dié rede dus vir die topleier ook aanvaarbaar te wees sonder dat dit aanstoot aan hom behoort te gee.

- Die raad se bedanking. Indien 'n direkteur nie tevrede met die vertoning van die topleier is nie en hy meen dat hy nie die nodige interne veranderinge teweeg sal kan bring nie, is daar geen ander alternatief oor as om te bedank nie. In die praktyk is daar talle redes wat as substituutredes vir sodanige optrede aangevoer kan word en word daar gewoonlik gevind dat die ware rede vir die bedanking nie verstrek word nie. Een van die redes vir hierdie traagheid is die feit dat die direkteur wat bedank moontlik verkeerd in sy oordeel mag wees en dat hy gevolglik so 'n verleentheidswekkende situasie wil voorkom. 'n Verdere rede is dat aangesien 'n direkteur gewoonlik 'n besige persoon is, hy dit nie as geregverdig ag om geweldig baie tyd aan 'n situasie te spandeer waar dinge besig is om skeef te loop nie. Die maklikste uitweg is dan om eenvoudig te bedank.

- Vra die topleier om te bedank. Hierdie is die laaste uitweg en kom relatief selde in die praktyk voor. Indien wel, word dit gewoonlik ook slegs met 'n groot mate van traagheid uitgevoer.

In Mace se studie word daar nog drie verdere rolle geidentifiseer wat gewoonlik van die raad van direkteure verwag word:

- Die bepaling van die basiese doelwitte, ondernemingstrategieë en die breë beleidsaspekte van die onderneming. 
- Die vra van skerpsinnige vrae - die funksie wat veral deur die studie van Copeland en Towl bekendheid verwerf het.

- Die aanwysing van die topleier.

Die interessantste bevindinge uit Mace se empiriese studie was egter dat, alhoewel die pasgenoemde drie funksies tradisioneel van die direksie verwag word, hierdie funksies nie in die praktyk deur die raad in groot en mediumgroot Amerikaanse vervaardigings-, mynbou- en kleinhandelsondernemings uitgevoet word nie. Die redes hiervoor sal nou vervolgens bespreek word.

\section{Die bepaling van basiese doelwitte, strategieë en beleidsaspekte}

Daar is bevind dat dit nie vir die raad van direkteure moontlik is om in besonderhede die basiese doelwitte, strategieë en beleidsaspekte te bepaal nie. Die rede hiervoor is dat hierdie funksies in 'n moderne organisasie gewoonlik so kompleks is dat dit slegs moontlik is met uitgebreide en tydrowende studie van die kant van die direkteure. Uiteraard word die strategieë in 'n belangrike mate bepaal deur die toewysing van kapitaalfondse aan verskillende projekte wat vir goedkeuring aan die raad voorgelê word. Hier is ook gevind dat die raad in talle gevalle slegs ' $n$ minimale of selfs geen bydrae maak nie weens die komplekse aard van die verskillende voorstelle.

\section{Die vra van skerpsinnige vrae}

Hierdie tradisionele rol van skerpsinnige vrae hou verband met besondere onderskeidingsvermoë en oordeelkundigheid deur ' $n$ direkteur. ' $n$ Werklike penetrerende vraag van hierdie aard kan 'n situasie ontbloot wat 'n grondige hersiening van 'n basiese beleidsrigting tot gevolg kan hê. 'n Voorbeeld van so 'n vraag is wanneer 'n direkteur sou vra waarom $20 \%$ van die klante meer as $85 \%$ van die totale verkoopsvolume verteenwoordig. So 'n vraag kan 'n herkonsiderasie van die hele organisasie se bemarkingsbeleid tot gevolg hê. 'n Ander voorbeeld is wanneer 'n direkteur vra wat die effek van sanksies of wêreldwye tekorte op die leweringsposisie van die organisasie sal wees, en dit opgevolg word deur ' $n$ breedvoerige studie oor hierdie aspekte.

Uit die aard van die saak kan 'n reguit en deurdringende vraag verleentheid in ' $n$ raadsvergadering skep. Daarom is dit dan nie verrassend dat Mace bevind het dat daar 'n traagheid by direkteure is om die topleier normaalweg op enige wyse in ' $n$ moeilike situasie te stel nie. Dit is natuurlik veral ook die geval as daar boonop nog van die topleier se ondergeskiktes self direkteure is of op die direksievergadering teenwoordig is. Om hierdie rede word daar dan dikwels van die belangrikste vrae buite die direksiekamer gevra wat dan eintlik van die werklike direksievergadering 'n klug maak.

Dit is dus duidelik dat die taktvolle wyse waarop ' $n$ direkteur ' $n$ vraag vra, 'n belangrike bydrae kan maak tot die besluit om sy gedagtegang verder op te volg. Andersins kan hy vind dat hy slegs daarin slaag om weerstand teen sy gedagtes, en moontlik ook teen homself, op te bou. Indien dit gebeur, mag hy dit al hoe moeiliker vind om konstruktiewe bydraes te maak en mag hy uiteindelik genoop word om te bedank.
Baie sal ook afhang van die volwasse gesindheid van die topleier in dié opsig of hy werklik 'moeilike' vrae verwelkom en of hy dit as 'n geleentheid sien om van die basiese aan. names in die organisasie te hersien en opnuut te deurdink. Indien dit nie sy ware gesindheid is nie, sal dit in die praktyk gou blyk en mag direkteure al hoe meer traag word om werklike deurdringende vrae te vra. Die vraag wat elke topleier homself dus moet vra is die volgende: 'Sien ek die skerpsinnige vrae wat direkteure vra as 'n geleentheid om my te help om die organisasie beter te bestuur? Of wil ek liewer hierdie vrae ongevraag sien?' Laasgenoemde houding sal onvermydelik op die langtermyn ' $n$ waarskynlike nadelige invloed op die welsyn van die organisasie hê.

\section{Aanwysing van die topleier}

Die aanwysing van die topleier is een van die funksies wat ook normaalweg van die raad van direkteure verwag word. Ook hier het Mace gevind dat hierdie funksie nie deur die raad uitgevoer word nie (behalwe in krisisgevalle), maar dat die topleier self die belangrikste invloed op die keuse van sy opvolger uitoefen. Die raad kies dus nie die bestuur nie, maar die bestuur kies eerder die direksie in baie gevalle. Goeie argumente kan daarvoor aangevoer word dat die topleier self sy opvolger aanwys. Hy is immers die beste vertroud met sy ondergeskiktes (indien 'n interne aanstelling beoog word) en hy behoort ook die beste te weet wat die vereistes van sy taak behels. Gevolglik neig die meeste rade in die praktyk om die aanbevelings van die topleier te aanvaar.

\section{Omskrywing van die aktiwiteite van die direksie}

In die Amerikaanse maatskappy Texas Instruments word tans heelwat pionierswerk gedoen oor wat die rol van direkteure behoort te wees. Volgens een van hulle direkteure, Bryan F. Smith, word daar al hoe meer 'n konsensus bereik dat die primêre funksie van die raad daarop gerig is om die maatskappy en die topbedryfsleier te evalueer. ${ }^{6}$ Die Amerikaanse wetgewing word dan ook al hoe meer daarop gerig om aan hierdie funksie wat as 'n 'monitor', 'oudit', of 'evaluering' beskryf word, verslag te doen.

Bogenoemde maatskappy het dan ook heelwat moeite gedoen om skriftelik uiteen te sit wat van 'n direkteur verwag word. Oor die algemeen word dit van direkteure verwag om voldoende op die hoogte te wees van die maatskappy se planne, operasies, en vertoning sodat die talryke funksies van die raad van direkteure op 'n effektiewe wyse uitgevoer kan word. Spesifiek word dit dan van direkteure verwag om die volgende te doen:

- Maandelikse en ander spesiale direksievergaderings by te woon.

- Beplanningsvergaderings van die maatskappy by te woon.

- Aanlegte en kantore van die maatskappy te besoek.

- Geleenthede soos die kwartaallikse finansiële verslagvergaderings by te woon.

- Deel te neem as lede en voorsitters van komitees van die raad.

- Spesifieke studies of ondersoeke namens die raad te onderneem en om daarna aan die raad verslag te doen. 
Die vergoedingsbeleid van genoemde maatskappy sal nie nou bespreek word nie, maar die belangrike beginsel waarvan kennis geneem moet word, is dat die aantal dae wat jaarliks van direkteure verwag word, eksplisiet gespesifiseer word. So word daar van ' $n$ algemene direkteur ' $n$ minimum van 15 dae per jaar verwag, waarvoor hy dan ook na behore vergoed word.

Die benadering om eenduidigheid op 'n skriftelike wyse te verkry van wat van 'n direkteur verwag word, is een wat sterk voorgestaan en onderskryf word. Slegs op hierdie wyse kan daar verseker word dat direkteure duidelikheid het van dit wat van hulle verwag word. Dit kan ook 'n metode wees waardeur daar van passiewe direkteure op 'n direksie ontslae geraak kan word.

\section{Samevatting}

Hoewel daar min navorsing oor die praktyke van SuidAfrikaanse direksies bestaan, is dit die indruk en ervaring van die skrywer dat die situasie hier te lande nie veel anders is as wat Mace bevind het nie. Die vraag wat dus ontstaan is wat moet die plaaslike topbedryfsleier en die verantwoordelike direkteur doen om die situasie te verbeter? Die samestelling van die raad en praktyke wat gevolg word soos die vergoedingsbeleid, kan 'n belangrike bydrae lewer om effektiewe direksies te skep. Bowenal gaan dit om die klimaat in 'n organisasie en die houding van die topleier om vir homself deur middel van sy direksie sy eksterne blik deur hulle meer uitgebreide omgewingsverkenning te verbeter.

\section{Summary}

The functions of the board of directors: Theory and Practice

Traditionally a number of functions are normally thought to be the responsibility of a governing board, usually known as the board of directors. One of the major expectations is that the board as the ultimate body responsible for the welfare of an organization, will be intimately responsible for setting the strategy of the organization. There are a number of inhibiting factors however, that occur in practice that often prevent boards from actually setting strategies themselves.
Some of these factors are a lack of detailed involvement, time and sometimes knowledge on the part of the member of the board. It is argued that rather than to perform the operational steps of setting strategies themselves, the board should assist in scanning the environment and be particularly concerned about the quality of the setting of strategies. As an overseer body, the board should perform an audit function to ensure strategies that are rationally set.

Specifically, this article identifies some of the factors that have placed additional pressure, such as a number of cases of bribery and the increasing public concern about the actions of public corporations. In a sense one can argue that this is a passive and reactive role. A more positive role is the active concern about setting strategies. Some of the legal requirements for a board are indentified both in the South African and American situations.

The typically accepted functions are next discussed and these include the achievement of stability, selection of the executive (particularly the top executive), setting of strategy, control and the asking of the so-called discerning questions. Reference is made to empirical studies which have found that the normally accepted functions are in fact not normally done. Particularly important is the disciplinary function and action in cases of crises situations. A problem in practice that also occurs is to ensure the active participation of directors - one way is to spell out the details of the expected involvement of a director in written form.

\section{Verwysings}

1. Cilliers, H.S., Benade, M.L. \& De Villiers, S.W.L. Maatskappyreg. Durban: Butterworths, 1977

2. Naude, S.J. Die Regsposisie van die Maatskappydirekteur. Durban: Butterworths, 1970

3. Copeland, M. T \& Towl, A.R. The Board of Directors and Business Management. Division of Research, Graduate School of Business Administration, Harvard University, Boston, 1947.

4. National Industrial Conference Board. Corporate Directorship Practices: Compensation 1977. A joint research report from the Conference Board and the American Society of Corporate Secretaries, by Jeremy Bacon, 1978.

5. Mace, M.L. Directors - Myth and Reality. Harvard University, Boston, 1971.

6. Smith, F.B. Interne ongepubliseerde dokument van Texas Instruments. Dallas, Texas, 1976 